\title{
DEM simulation of particle descending velocity distribution in the reduction shaft furnace
}

\author{
Kuan Xu and Ming-hua Bai \\ National Engineering Research Center for Equipment and Technology of Cold Strip Rolling, Yanshan \\ University, No. 438 Hebei Avenue, Qinhuangdao 066004, Hebei, P.R. China \\ e-mail: bmh@ysu.edu.cn
}

Key words:

Discrete element method; shaft furnace; screw feeder; descending velocity

\begin{abstract}
Reduction shaft furnace is a promising alternative to blast furnace ironmaking. The particle descending velocity distribution has a great influence on the shaft furnace, which directly affects the production index and further the shaft furnace normal smelting. Therefore, a three-dimensional model (3D) is established based on the discrete element method (DEM) and computation fluid dynamic (CFD). The effect of the gas flow in the shaft furnace, the height, the diameter and the bosh angle of the shaft furnace on the particle descending velocity distribution during discharging process is investigated by the model and analyzed based on the granular dynamic theory and Janssen theory. The results show that the particle velocity reduces along the radius. The effect of the gas flow on the velocity distribution is insignificant. In order to obtain a uniform velocity distribution, it is better to increase the height, or the diameter, or to decrease the bosh angle. An improved model is proposed for the uniform velocity distribution at last.
\end{abstract}

ecause of its fast reduction rates, consistent product quality, minimal environmental impacts, and great flexibility, reduction shaft furnace is a promising alternative to blast furnace ironmaking [1]. In the shaft furnace production, iron ore particles are charging in the shaft furnace, and the reducing gas having high temperature is blown from tuyeres, then the particles are reduced during descending. If the particle descending velocity distribution is not reasonable, the iron ore particles will not be reduced better, causing the production index decreases and further affecting the shaft furnace normal smelting. Consequently, it is necessary to focus on researching the particle descending velocity distribution in the shaft furnace.

Hence many researches had been investigated about the solid flow [2-6], these results are helpful for an overall understanding of the solid flow. To sum up, there have been two approaches adopted for the solid flow research, such as the physical simulation [24] and the mathematical simulation $[5,6]$. Compared with the mathematical simulation, the physical simulation is hard to analyze the solid flow quantificationally. Kou et al. [5] researched the effect of the bottom diameter of COREX shaft furnace, the cylinder height and the screw flight diameter on the particle velocity distribution based on DEM. However, the model he developed is not taken into account the effect of the gas flow in the shaft furnace, the height, the diameter and the bosh angle of the shaft furnace on the particle descending velocity.

Numerical simulation analysis for solid flow in shaft furnace is a useful tool to understand the behavior of solid flow. So far, DEM has become one of the most powerful simulation methods for granular behaviors. In the ironmaking field, many researches [5-8] had been studied about the granular behavior based on DEM, and the simulation results coincided well with the experiments and industrial operation. It can be found that DEM is well developed and useful to investigate the granular behavior after comparing the results with previous work.

Janssen theory, originated from Janssen [9], has become one of the most powerful methods for calculating the stresses in granular layer. It is applied in civil engineering, such as hopper and 
Table 1. Forces and torques acting on particle $i$.

\begin{tabular}{ll}
\hline \multicolumn{1}{c}{ Force and torque } & \multicolumn{1}{c}{ Equation } \\
\hline Normal contact force, $\mathbf{f}_{c n, i j}$ & $-(4 / 3) E^{*} \sqrt{R} \delta_{n}^{3 / 2} \mathbf{n}$ \\
Normal damping force, $\mathbf{f}_{d n, i j}$ & $-c_{n}\left[6 m_{i j} E^{*}\left(R^{*} \delta_{n}\right)^{1 / 2}\right]^{1 / 2} \mathbf{V}_{n, i j}$ \\
Tangential contact force, $\mathbf{f}_{c t, i j}$ & $-\mu_{s}\left|\mathbf{f}_{c n, i j}\right|\left(1-\left(1-\delta_{t} / \delta_{t, \max }\right)^{3 / 2}\right) \hat{\delta}_{\mathbf{t}}$ \\
Tangential damping force, $\mathbf{f}_{d t, i j}$ & $-c_{t}\left(6 \mu_{s} m_{i j}\left|\mathbf{f}_{c n, i j}\right| \sqrt{1-\delta_{t} / \delta_{t, \max }} / \delta_{t, \max }\right)^{1 / 2} \mathbf{V}_{t, i j}$ \\
Coulomb friction force, $\mathbf{f}_{t, i j}$ & $-\mu_{s}\left|\mathbf{f}_{c n, i j}\right| \hat{\delta}_{t}$ \\
Torque by tangential forces, $\mathbf{T}_{t, i j}$ & $\mathbf{R}_{i j} \times\left(\mathbf{f}_{c t, i j}+\mathbf{f}_{d t, i j}\right)$ \\
Rolling friction torque, $\mathbf{T}_{r, i j}$ & $\mu_{r, i j}\left|\mathbf{f}_{c n, i j}\right| \hat{\omega}_{i j}^{n}$ \\
Particle-fluid drag force, $\mathbf{f}_{d f, i}$ & $0.125 C_{d 0, i} \rho_{f} \pi d_{p i}^{2} \varepsilon_{i}^{2}\left|\mathbf{u}_{i}-\mathbf{v}_{i}\right|\left(\mathbf{u}_{i}-\mathbf{v}_{i}\right) \varepsilon_{i}^{-\chi}$ \\
Pressure gradient force, $\mathbf{f}_{p g, i}$ & $-V_{i} \nabla p_{i}$ \\
\hline
\end{tabular}

where $1 / m_{i j}=1 / m_{i}+1 / m_{j}, 1 / R^{*}=1 / R_{i}+1 / R_{j}, E^{*}=E /\left[2\left(1-v^{2}\right)\right], \hat{\omega}_{i j}^{n}=\omega_{i j}^{n} /\left|\omega_{i j}^{n}\right|, \hat{\omega}_{i j}^{n}=\omega_{i j}^{n} /\left|\omega_{i j}^{n}\right|, \delta_{t}=$ $\left|\delta_{t}\right|, \hat{\delta}_{t}=\delta_{t} /\left|\delta_{t}\right|, \mathbf{R}_{i j}=R_{i}\left(\mathbf{r}_{j}-\mathbf{r}_{i}\right) /\left(R_{i}+R_{j}\right), \delta_{t, \max }=\mu_{s} \delta_{n}(2-v) /(2(1-v)), \mathbf{v}_{i j}=\mathbf{v}_{j}-\mathbf{v}_{i}+\omega_{j} \times \mathbf{R}_{j}-\omega_{i} \times$ $\mathbf{R}_{i}, \mathbf{v}_{n, i j}=\left(\mathbf{v}_{i j} \cdot \mathbf{n}\right) \cdot \mathbf{n}, \mathbf{v}_{t, i j}=\left(\mathbf{v}_{i j} \times \mathbf{n}\right) \times \mathbf{n}, \varepsilon_{i}=1-\sum_{i=1}^{k} V_{i} / \Delta V, \chi=3.7-0.65 \exp \left[-\left(1.5-\log _{10} R e_{i}\right)^{2} / 2\right], C_{d 0, i}=$ $\left(0.63+4.8 / \operatorname{Re}_{i}^{0.5}\right)^{2}, \operatorname{Re}_{i}=\rho_{f} d_{p i} \varepsilon_{i}\left|\mathbf{u}_{i}-\mathbf{v}_{i}\right| / \mu_{f}$.

Note that tangential force $\left(\mathbf{f}_{c t, i j}+\mathbf{f}_{d t, i j}\right)$ should be replaced by $\mathbf{f}_{t, i j}$ when $\delta_{t} \geqq \delta_{t, \max }$

flat-bottomed bin designs, and further investigated by many researchers [10-12].

In this work, a 3D model of the shaft furnace is established by a combined CFD and DEM approach. The influence of the gas flow in the shaft furnace, the height, the diameter and the bosh angle of the shaft furnace on the particle descending velocity is further investigated by the established model and analyzed based on the granular dynamic theory and Janssen theory. An improved model is proposed in order to achieve a uniform velocity distribution in the shaft furnace in the end.

\section{Model description}

In this work, the gas-solid flow in the shaft furnace is regarded as be composed of a discrete solid phase and a continuum fluid phase (the fluid phase is air). The discrete solid phase is described based on DEM. A particle has two types of motion: translational and rotational. During its movement, the particle may interact with the neighboring particles and/or the walls at the contact points and interact with the surrounding fluid phase $[13,14]$. At any time $t$, the governing equations for particle $i$ with radius $R$, mass $m_{i}$ and moment of inertia $I_{i}\left(=2 / 5 m R^{2}\right)$ can be expressed as follows:

$$
\begin{gathered}
m_{i} \frac{d \mathbf{v}_{i}}{d t}=\mathbf{f}_{p f, i}+\sum_{j=1}^{K}\left(\mathbf{f}_{c n, i j}+\mathbf{f}_{d n, i j}+\mathbf{f}_{c t, i j}+\mathbf{f}_{d t, i j}\right) \\
\quad+m_{i} \mathbf{g} \\
I_{i} \frac{d \omega_{i}}{d t}=\sum_{j=1}^{K}\left(\mathbf{T}_{t, i j}+\mathbf{T}_{r, i j}\right)
\end{gathered}
$$

where $\omega_{i}$ and $\mathbf{v}_{i}$ are the angular velocity and translatory velocity of particle $i$. $K$ is the number of the particles in contact with the particle $i$. The forces involved are the gravity $m_{i} \mathbf{g}$, the particle-fluid interaction force $\mathbf{f}_{p f, i}$ which includes two parts: the drag and pressure gradient forces, $\mathbf{f}_{d f, i}$ and $\mathbf{f}_{p g, i}$, and the inter-particle forces between particles: the tangential and normal contact forces, $\mathbf{f}_{c t, i j}$ and $\mathbf{f}_{c n, i j}$, and the damping forces in tangential and normal directions, $\mathbf{f}_{d t, i j}$ and $\mathbf{f}_{d n, i j}$. The torque acting on particle $i$ because of particle $j$ includes the tangential torque $\mathbf{T}_{t, i j}$ and the rolling friction torque $\mathbf{T}_{r, i j}$. The equations used for the present simulation are the same as those used in the previous work [14-20], as listed in Table 1.

The continuum fluid phase is described in a way which is similar to the one widely used in the usual two-fluid model. The fluid governing equation is obtained on the basis of the point equation of motion of the fluid 


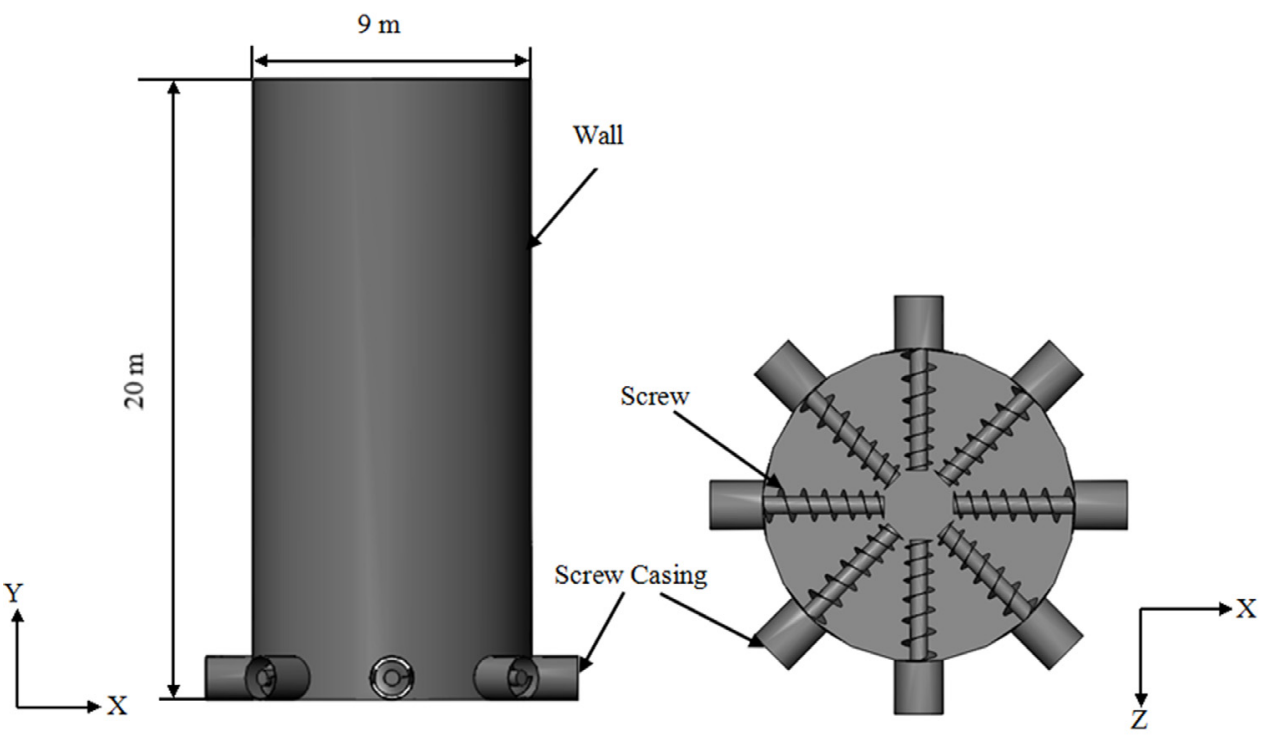

Fig. 1. The shaft furnace model used in this simulation.

and the solid phase governing equation is derived on the basis of the equation of motion for the center of mass of a single particle. The mass conservation and the momentum conservation in terms of the local averaged variables over a computational cell can be expressed as follows:

$$
\begin{aligned}
\partial\left(\rho_{f} \varepsilon_{f}\right) / \partial t+\nabla \cdot\left(\rho_{f} \varepsilon_{f} \mathbf{u}\right)= & 0 \\
\partial\left(\rho_{f} \varepsilon \mathbf{u}\right) / \partial t+\nabla \cdot\left(\rho_{f} \varepsilon \mathbf{u u}\right)= & -\nabla p-\mathbf{F}_{f p} \\
& \quad+\nabla \cdot \tau+\rho_{f} \varepsilon \mathbf{g}
\end{aligned}
$$

where $\mathbf{F}_{f p}$ and $\tau$ are, respectively, the volumetric particle-fluid interaction force in a computational CFD cell of volume $\Delta V$ and the fluid viscous stress tensor which are given as $\mathbf{F}_{p f}=\left(\sum_{i=1}^{k_{c}} \mathbf{f}_{p f}\right) / \Delta V$, and $\tau=$ $\mu_{f}\left[(\nabla \mathbf{u})+(\nabla \mathbf{u})^{-1}\right] . \mathbf{u}$ and $\varepsilon$ are the fluid velocity and the porosity which is given as $\varepsilon=1-\left(\sum_{i=1}^{k_{c}} V_{p, i}\right) / \Delta V$.

The method for CFD-DEM simulations has been well established [20-22]. The method used in this work is the same as before, not described here for brevity.

\section{Model simulation}

Since our aim here is to establish a general understanding of the influence of the gas flow in the shaft furnace, the height, the di-
Table 2. Particle conditions in the simulation.

\begin{tabular}{ccccc}
\hline Parameters & Small & Middle & Large & Unit \\
\hline Diameter & 100 & 200 & 300 & $\mathrm{~mm}$ \\
Mass ratio & 33.3 & 33.3 & 33.3 & $\mathrm{wt} \%$ \\
\hline
\end{tabular}

ameter and the bosh angle of the shaft furnace on the particle descending velocity distribution, a simplified shaft furnace model is used to reduce the computational requirement while reasonable and general results can be acquired. For example the shaft furnace wall is designed vertical in the model. However, it doesn't affect the laws and results on the particle descending velocity distribution. The 3D model of the shaft furnace is shown in Figure 1. As the number of the particles in the shaft furnace is over hundreds of millions and the particles sizes range widely, it will spend numerous time carrying out the calculation according to the actual sizes of particles. Enlarging the particle size is a common practice in process modeling by DEM or CDF-DEM approach [23]. In addition, according to Kou [5], enlarging the particle size and changing the particle size distribution have insignificant influence on particle descending velocity distribution. Therefore, the particle diameter is enlarged and the condition of the particle is listed in Table 2.

The geometries in the 3D model, include the shaft furnace wall and the 
Table 3. Parameters used in the simulation.

\begin{tabular}{ccccc}
\hline Parameters & Screw & Particle & Wall & Unit \\
\hline Density & 7850 & 3425 & 7850 & $\mathrm{kg.m}$ \\
Shear modulus & $7.9 \mathrm{E} 10$ & $1 \mathrm{E} 7$ & $7.9 \mathrm{E} 10$ & $\mathrm{~Pa}$ \\
Poission's ratio & 0.3 & 0.25 & 0.3 & - \\
Static friction cofficient & 0.364 & 0.5 & 0.4 & - \\
Rolling friction cofficient & 0.05 & 0.05 & 0.05 & - \\
Restitution cofficient & 0.5 & 0.6 & 0.5 & - \\
\hline Time step & \multicolumn{4}{c}{$10^{-5}$} \\
\hline
\end{tabular}

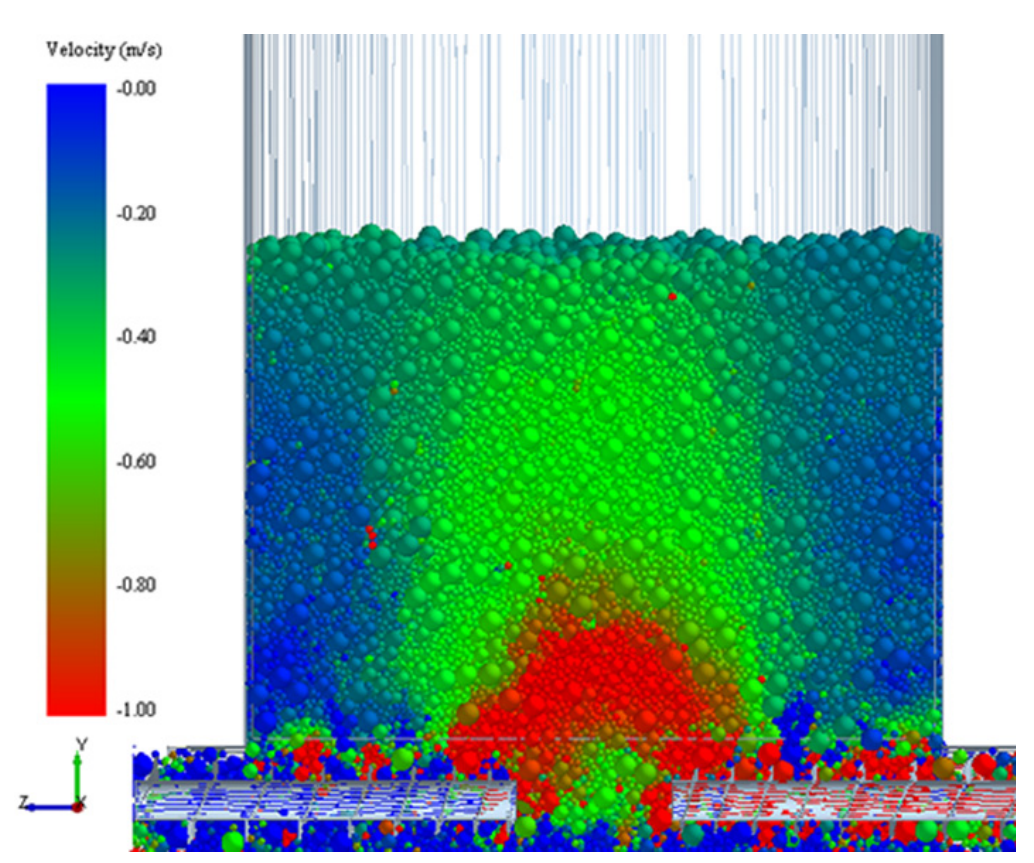

Fig. 2. The particle descending velocity distribution( the gas velocity is $0 \mathrm{~m} . \mathrm{s}^{-1}$ ).

screws, are made of steel. According to Fernandez [24] and Kou [5], because the screw may be polished by the particle flow, the static friction coefficient between the screw surface and particle is set as 0.364 . The simulation parameters are collected in Table 3 [5, 8, 17, 25, 26].

In practical production, it spends $6-7 \mathrm{~h}$ extruding these particles out of the shaft furnace. Since $1 \mathrm{~s}$ movements of the particles cost almost $1 \mathrm{~h}$ calculation time in average according to the simulation, it is almost impossible to carry out the simulation. According to Owen's, Cundall's and Thompson's works [27-30], the particle flow and the average particle velocity are linear functions of the screw rotating speed from 200 RPM to 1400 RPM for horizontal screw conveyor. Thus, in order to reduce the calculation time, the screw rotating speed is accelerated in this simulation.
In this simulation, the shaft furnace is initially filled with the well-mixed particles mention above. Then, the gas is introduced at the shaft furnace bottom, and the particles are settled under gravity, particle-fluid drag force and pressure gradient force to reach a macroscopically static state. After that, the screws start to rotate around their own axes at a given time for the simulation.

In practical production, there is a complicated thermo-chemical behavior in the shaft furnace. However, this work only investigate the influence of the gas flow in the shaft furnace on the particle descending velocity distribution, the complicated thermochemical behavior will be investigate in the future. The particle descending velocity distribution when the gas velocity is $0 \mathrm{~m} . \mathrm{s}^{-1}$ is illustrated in Figure 2, where the red particle means large descending velocity, while the blue one means small velocity. 


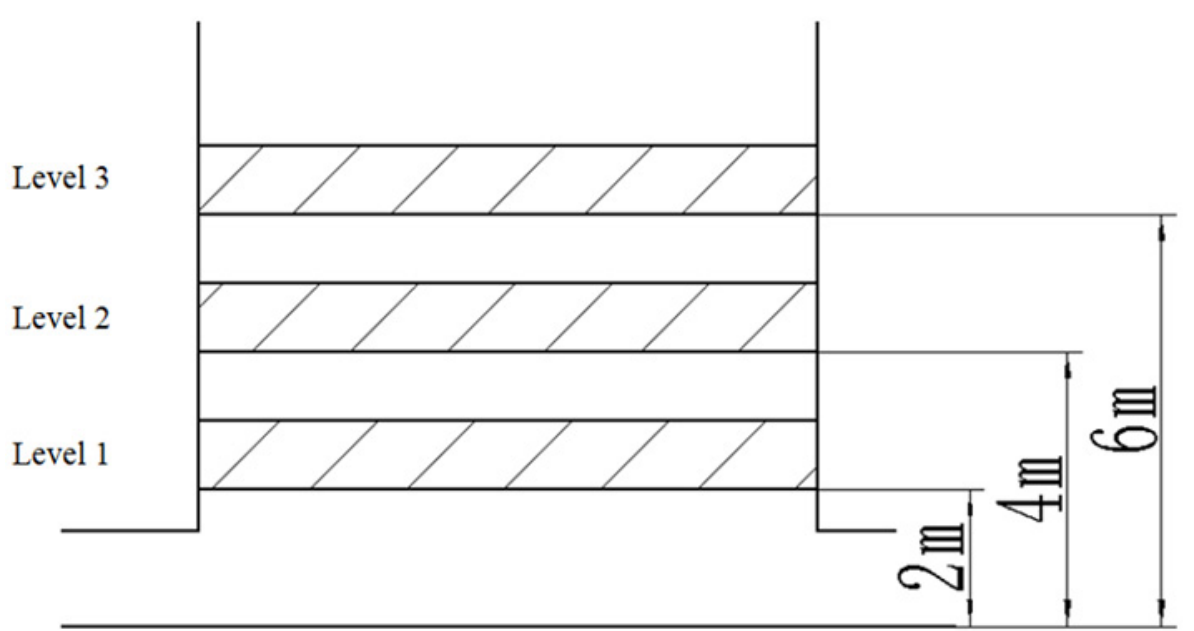

Fig. 3. Schematic diagram of the different levels.

It can been seen that the particle descending velocity distribution is nonuniform in this discharging process. The red area (the central area of the shaft furnace) means that the particles have the largest descending velocity in there, because the effect of the first screw blade is quite large and direct for the particle movement, which is also found in Kou's and Yu's works $[5,31]$. The particle velocity reduces with the increase of the height from the shaft furnace bottom and from the center to the wall areas.

In order to obtain the particles descending velocities along the radial direction, three levels are examined. The schematic diagram of different levels is illustrated in Figure 3.

Because the X-direction velocity and the Z-direction velocity of the particle are too slight to be considered, the Y-direction velocity of the particle is the research object in this work. According to Kou [5], the particle descending velocities around circumferential direction almost have no difference at the same radius and depth. A series of rings with $1 \mathrm{~m}$ height and same thickness are extracted from the levels to measure the particle descending velocities along the radius. The average of velocities in the rings are calculated and used to represent the particle descending velocities along the radius, which are presented in Figure 4.

It can be obtained that the particle descending velocities in each level decrease along radial direction. In addition, the par- ticle descending velocity distribution is the most inhomogeneous in level 1 (the maximum velocity difference is $0.742 \mathrm{~m} \cdot \mathrm{s}^{-1}$ ), while it is the most uniform in level 3 (the maximum velocity difference is $0.186 \mathrm{~m} . \mathrm{s}^{-1}$ ). The standard deviations of the particle descending velocities in each level are calculated in order to estimate the particle descending velocity fluctuations in each level. The standard deviation from level 1 to level 3 are $0.312,0.156$ and 0.082 , which implies that the particle descending velocity fluctuation is relatively even in higher level of the shaft furnace, while it becomes acutely in lower level of the shaft furnace. Thus, in order to obtain a uniform velocity distribution which is important to the discharging process, it is necessary to investigate the particle descending velocities along the radius at different conditions.

\section{Results and discussion}

The influences of some factors are investigated in this work, like gas flow in the shaft furnace, height, diameter and bosh angle of the shaft furnace.

\subsection{Gas flow}

Here, the effect of gas flow is discussed at different gas velocities in the shaft furnace. It can be noted that the similarity between drag and gravitational force is not satisfied in the 


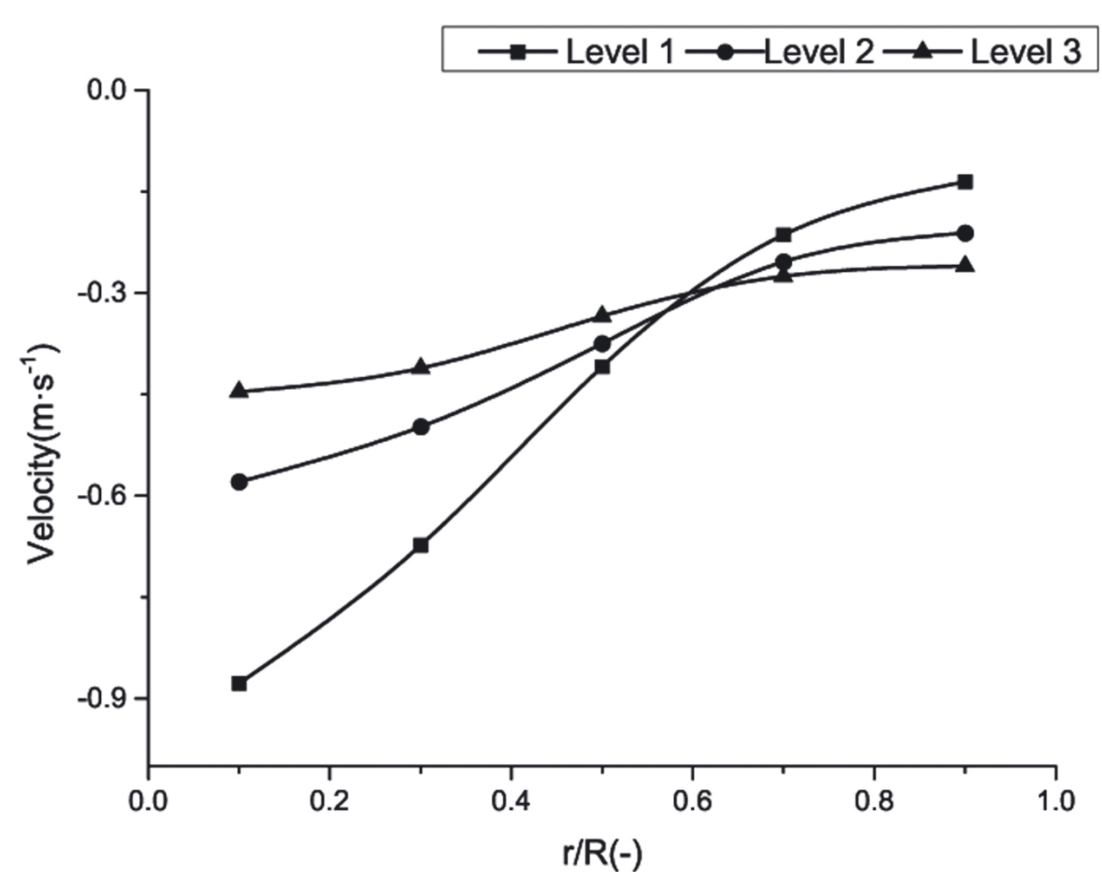

Fig. 4. The particle descending velocities along the radius.

calculation using larger particle size than the actual particle size. However, the effect can be negligible under the considered condition because solid flow is dominant and gas flow plays a minor role.

Figure 5 shows the velocity distributions at different gas velocities.

It can be seen that there are almost no difference between Figures $5 a-5 c$, which implies the effect of the gas velocity on the velocity distribution is insignificant under the considered conditions. Therefore, the velocities along the radius at different gas velocities in the three levels are extracted and shown in Figure 6 in order to analyze the phenomenon quantificationally.

In all levels, the particle descending velocity distributions are almost the same at different gas velocities. In addition, the wall normal stresses at different gas velocities in level 1 are measured and analyzed, the result shows that the wall normal stresses under the current conditions are almost no difference (the maximum difference is less than $5 \%$ ). The reason is that the gas-solid interaction forces are too small to affect the particle movement under the current conditions.

However, a phenomenon is found that the velocity distributions at different parti- cle layer height in the same level exist obvious differences. Therefore, a hypothesis is proposed that different shaft furnace heights may affect the velocity distribution.

\subsection{Shaft furnace height}

The velocities along the radius at different particle layer heights $(8 \mathrm{~m}, 10 \mathrm{~m}$ and $13 \mathrm{~m})$ are measured and analyzed respectively in order to investigate the influence of the shaft furnace height on the velocity distribution. The results of the velocity distribution are shown in Figures 7 and 8.

In Figure 7, it can be seen that the high descending velocity area is shrinking with the increase of particle layer height. This can be also found in all levels of Figure 8, the particle velocities in the center area $(0-0.5 R)$ reduce with the particle layer height increasing, and the differences between the maximum and minimum velocities in each level turn to smaller. For example, in the case of the layer height is $13 \mathrm{~m}$, the descending velocities at $0.1 R$ from level 1 to level 3 decrease by $13.5 \%, 31.4 \%, 27.1 \%$ respectively comparing with the layer height is $8 \mathrm{~m}$. The standard deviations of the velocities at different layer heights are listed in Table 4. 


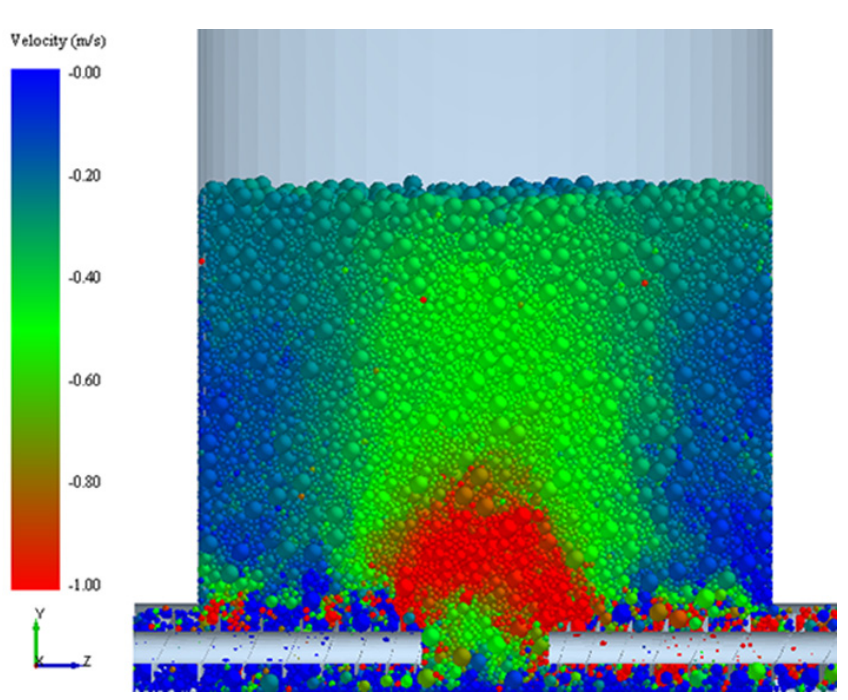

(a)

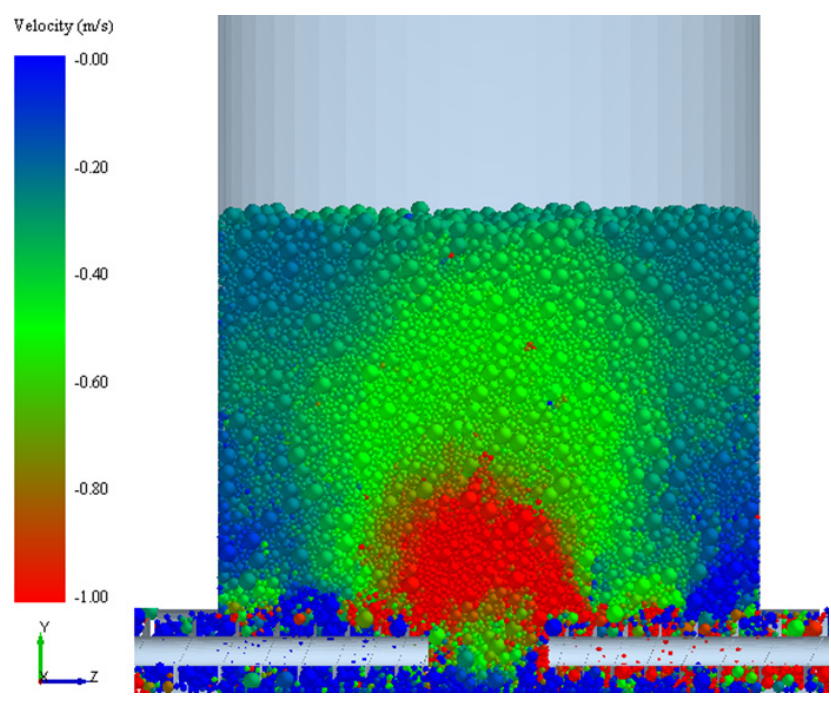

(b)

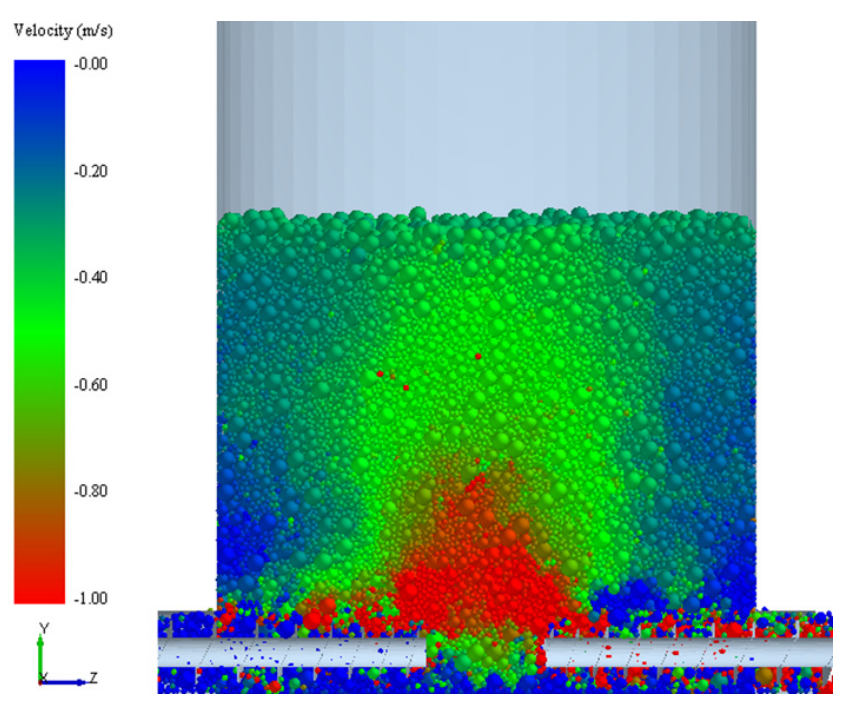

(c)

Fig. 5. Velocity distributions at different gas velocities (a) $0 \mathrm{~m} \cdot \mathrm{s}^{-1}$ (b) $2 \mathrm{~m} \cdot \mathrm{s}^{-1}$ (c) $4 \mathrm{~m} \cdot \mathrm{s}^{-1}$.

Table 4. Standard deviations of the velocities at different layer heights.

\begin{tabular}{cccc}
\hline Height & Level 1 & Level 2 & Level 3 \\
\hline $13 \mathrm{~m}$ & 0.233 & 0.043 & 0.009 \\
$10 \mathrm{~m}$ & 0.264 & 0.091 & 0.022 \\
$8 \mathrm{~m}$ & 0.312 & 0.156 & 0.082 \\
\hline
\end{tabular}

It can be found that the standard deviations of each level decrease with the layer height increasing, which implies that the relative motion between the particles turn to smaller and the velocity distribution becomes more uniform with the height increasing. It shows that the forces on the particles in the furnace under different shaft furnace height conditions are different, because force is the root cause of motion change. Therefore, the force on the particles in the furnace should be study.

According to granular dynamic theory [32], the reason of the relative motion between particles is that the shear force on the granular layer is larger than the antishearing force. The anti-shearing force can be written as follow.

$$
F_{s}=F_{r} f+C A
$$

where $F_{r}$ represents the normal force which is perpendicular to the shear direction, $f$ 


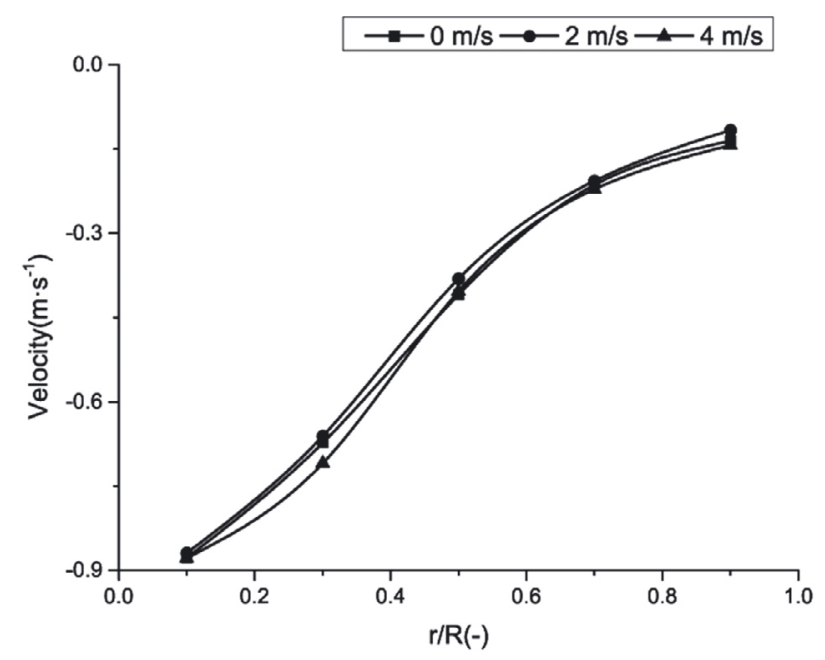

(a)

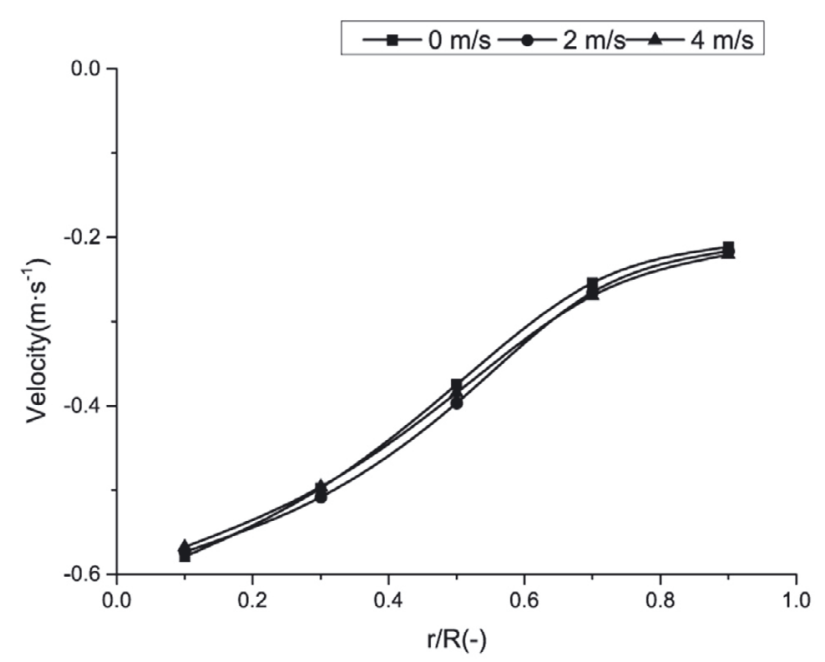

(b)

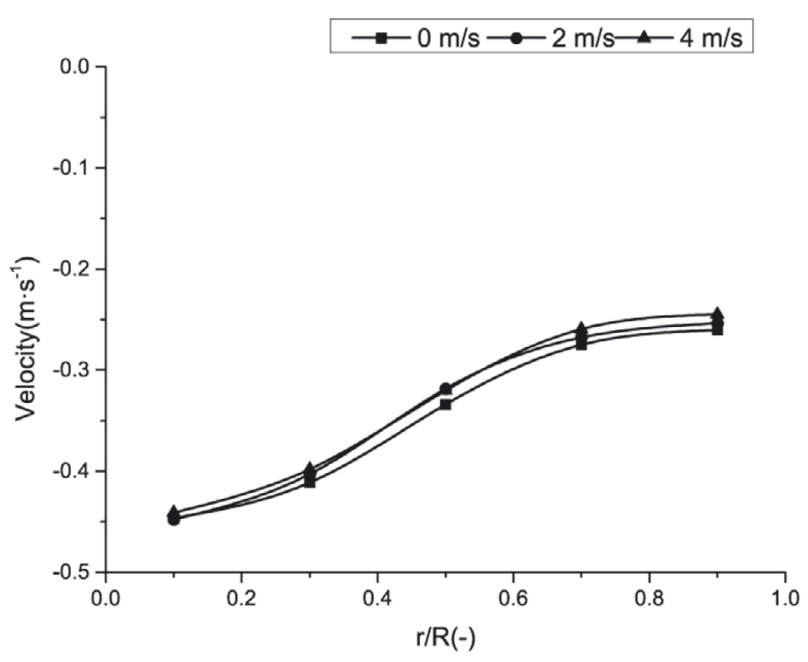

(c)

Fig. 6. Velocities along the radius at different gas velocities (a) level 1 (b) level 2 (c) level 3.

represents the granular friction coefficient. $C$ represents the unit cohesion which is defined as the cohesion on the unit shear plane and $A$ represents the shear area. It can be seen that $f$ and $C$ are constant in this work (the unit cohesion is 0), which implies that the normal force changes with the change of the layer height. According to Janssen theory [9-12], the axial stress and the radial stress in the granular layer are given by

$$
\begin{array}{r}
P_{a}=\frac{\rho g D}{4 k \lambda}\left(1-e^{\frac{-4 k \lambda z}{D}}\right) \\
P_{r}=k P_{a}=\frac{\rho g D}{4 \lambda}\left(1-e^{-\frac{4 k \lambda z}{D}}\right)
\end{array}
$$

where $z$ denotes the calculated height which is the distance from the granular layer surface. $\lambda$ and $\rho$ denote the friction coefficient between the particle and the wall and the bulk density of the granular layer, respectively. $k$ is a constant defining the ratio between the radial and axial stresses.

According to Equations (5)-(7), the radial and axial stresses increase with the increase of the shaft furnace height, and the anti-shearing force turns to larger, which reduces the relative motion between the particles. It is the reason that the velocity distribution becomes more uniform with the height increasing. In addition, in the level 3, the 


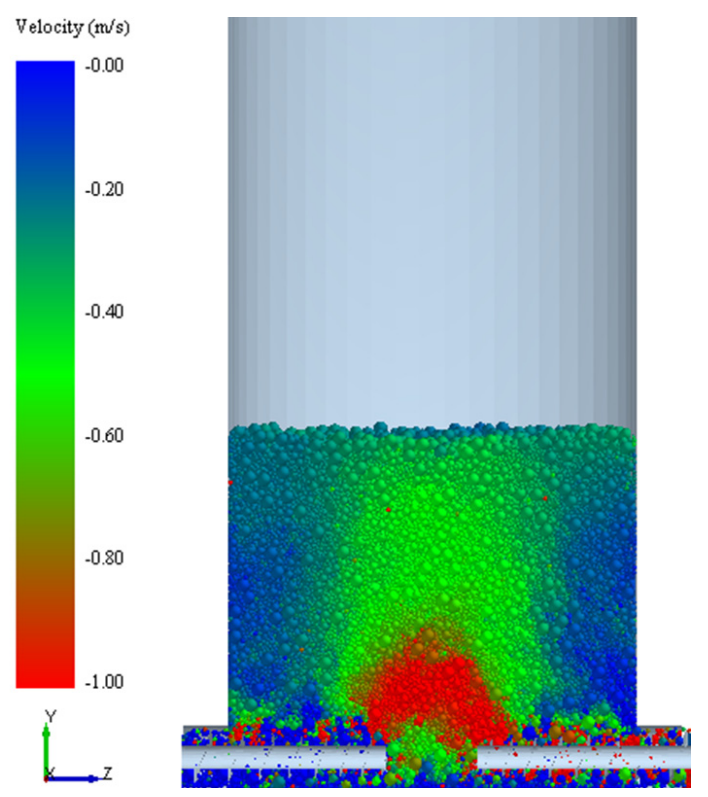

(a)

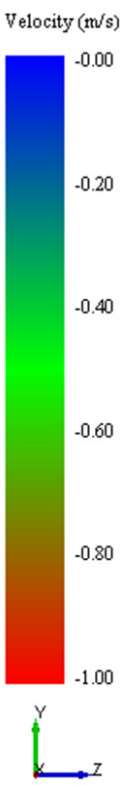

0.20

$-0.40$

$-0.60$

.0 .80

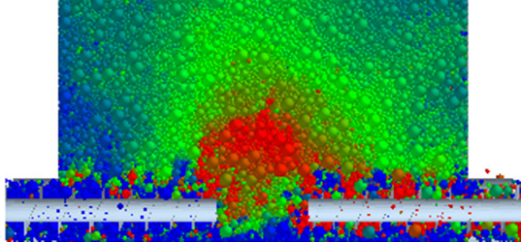

(b)

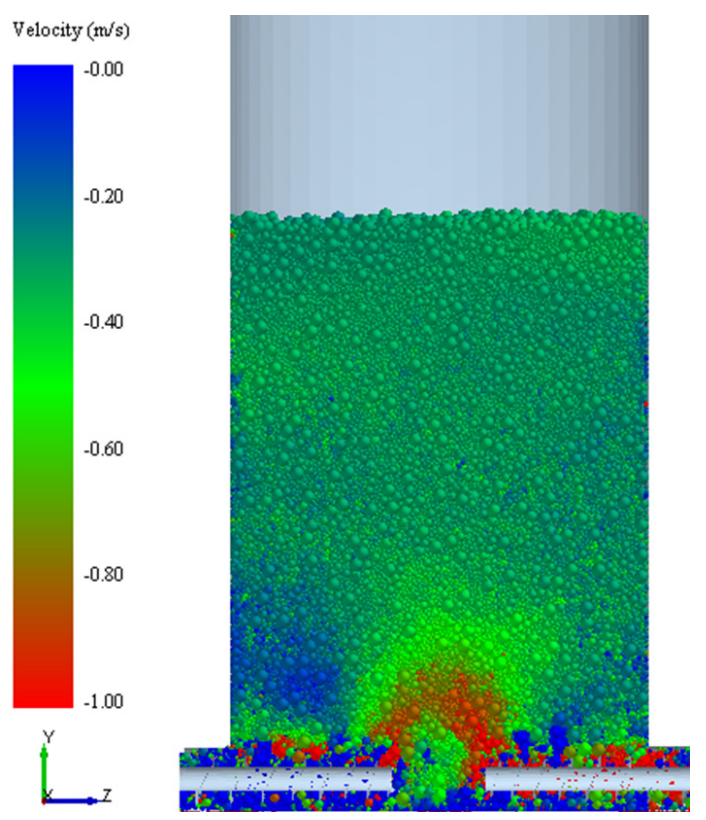

(c)

Fig. 7. Velocity distributions at different layer height (a) $8 \mathrm{~m} \mathrm{(b)} 10 \mathrm{~m}$ (c) $13 \mathrm{~m}$.

difference between the velocity distribution in the case of the layer height is $8 \mathrm{~m}$ and the other cases is obvious, because the distance from the granular layer surface to level 3 in the case of the layer height is $8 \mathrm{~m}$ is so much tinier that the stresses is quite smaller compare with the other cases. It can be found from Figure 8 that the change trends of the velocity at different heights in each level are almost identical, and if the particle descend- ing velocity distribution in the lower part of the shaft furnace is uniform, the one in the higher part is more uniform. Hence, only the velocities in level 1 are analyzed in the following study.

According to Equations (5) and (6), the effect of the increase of the height on the load on the particles in the furnace bottom gradually reduces with the height increasing. For the further investigate the effect of 


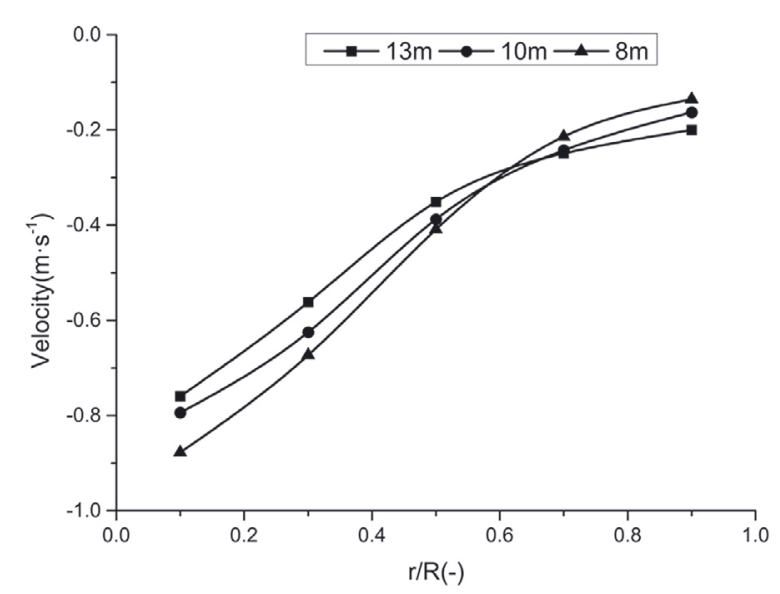

(a)

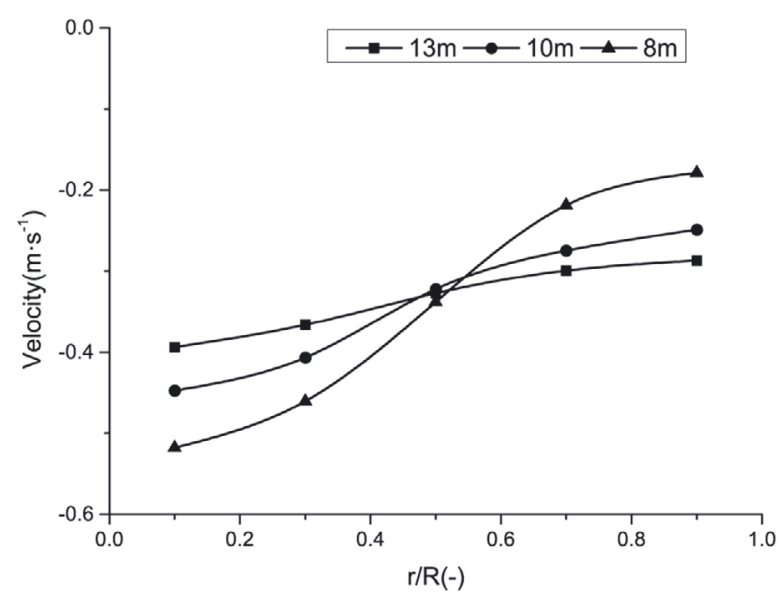

(b)

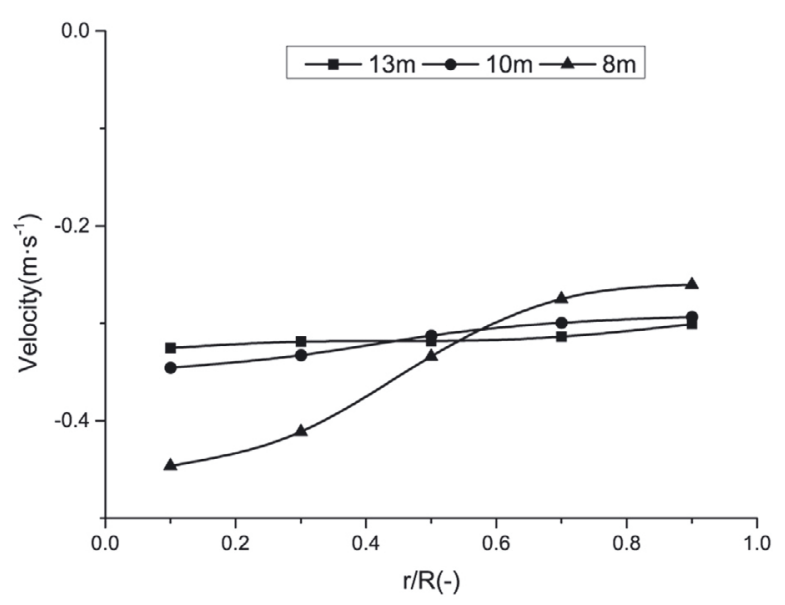

(c)

Fig. 8. Velocity along the radius at different heights of the pellets layer (a) level 1 (b) level 2 (c) level 3.

the shaft furnace height on the velocity distribution, a new shaft furnace model which is increased the height is established, and the velocity distributions in level 1 at different layer heights are illustrated in Figure 9.

It can be seen that the change of the velocity distribution decreases with the height increasing, and the change is insignificant after the height reached $30 \mathrm{~m}$, which implies that the height has little influence on the velocity distribution after the hight reached $30 \mathrm{~m}$ (hereafter referred as "maximum height") under the considered conditions.

\subsection{Shaft furnace diameter}

It can be found that the shaft furnace diameter has influence on the stresses on the particles according to Equations (5) and (6). In this section, the effect of the shaft furnace diameter on the velocity distribution is investigated. In order to eliminate the effect of the screws on the velocity distribution, the flight diameter and the pitch of the screw change to be constant in this section. Figure 10 shows the velocity distributions at different the shaft furnace diameters when the layer heights are identical.

In Figure 10, the high velocity area at the center of the shaft furnace bottom reduces with the shaft furnace diameter increasing, while the low velocity area near the wall increases. The velocities in level 1 along the radius are illustrated in Figure 11 in order to quantificationally investigate the phenomenon. 


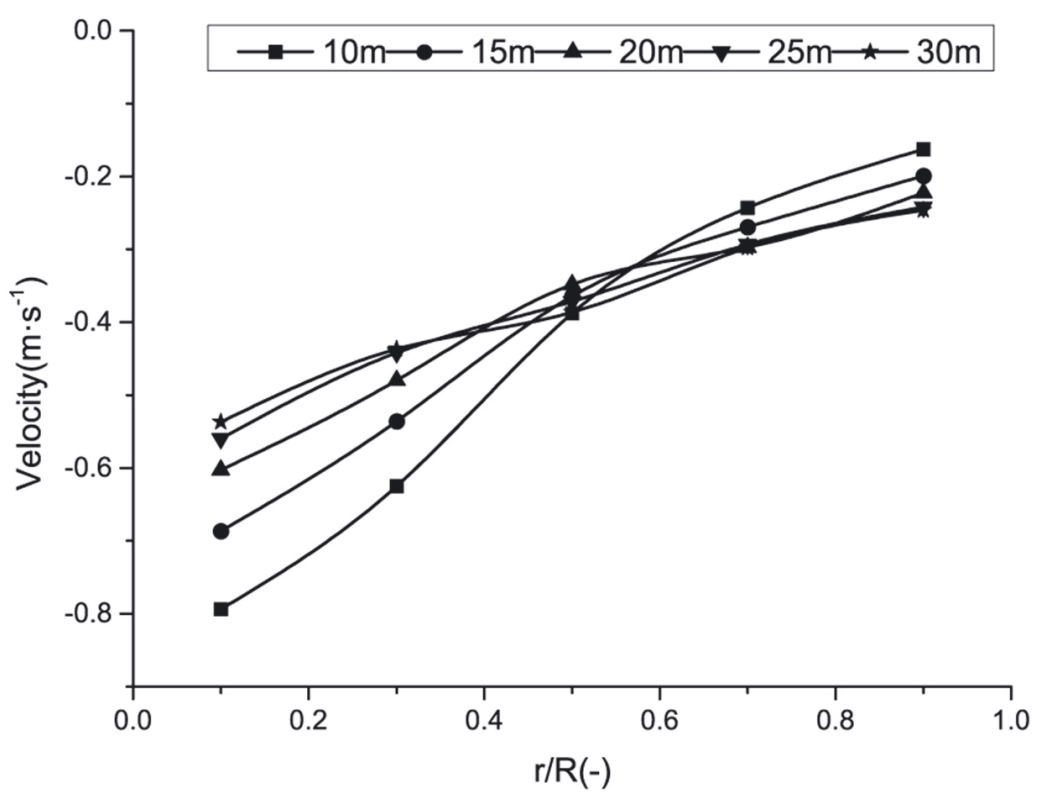

Fig. 9. Velocity along the radius in level 1 at different heights of the pellets layer.

It can be seen from Figure 11 that the center area velocities turn to smaller with the increase of diameter, while the velocities in the middle area (the radius from $1.5 \mathrm{~m}$ to $3 \mathrm{~m}$ ) increase slightly. Specifically, the decrease of the center area velocity is obvious, the velocity in the case of $10 \mathrm{~m}$ shaft furnace diameter decreases by $17.0 \%$ compared with that of $8 \mathrm{~m}$. In addition, the unit distance change of the velocity along the radial direction decreases with the diameter increasing. It implies that the relative motion between the particles turn to smaller which is caused by the increase of the stresses on the particles. However, with the increase of the diameter, the low velocity area near the wall increases. In order to reduce the low velocity area near the wall, and obtain the uniform of drawdown patterns, the effect of the shaft furnace bosh angle on the velocity distribution should be studied.

\subsection{Shaft furnace bosh angle}

To investigate the effect of the shaft furnace bosh angle on the velocity distribution, the $3 \mathrm{D}$ model is reestablished and the schematic diagram of shaft furnace model is presented in Figure 12, and the cross-sections of veloc- ity distribution at different bosh angles $\left(90^{\circ}\right.$, $85^{\circ}$ and $80^{\circ}$ ) are illustrated in Figure 13.

It can be seen that with the decrease of the shaft furnace bosh angle, the low velocity area near the wall turn to smaller and the velocities at the center area reduce. The velocity distributions in level 1 at different shaft furnace bosh angles are illustrated and analyzed in Figure 14.

In Figure 14, it can be found that with the decrease of the shaft furnace diameter, the velocities within $0.4 R$ reduce, while the velocities at other areas turn to larger. The reason is that the shaft furnace cross sections are gradually reduced from the top to the bottom, which leads to the rearrangement of the particles in order to adapt the decrease of the cross sections and the increase of the extrusion between the particles. In addition, the extrusion between the particles turns to larger with the cross section contraction ratio increasing.

\subsection{The improved model}

According to the above simulation results, the height and the diameter of the shaft furnace should be increased while the bosh angle of the shaft furnace should be reduced in 


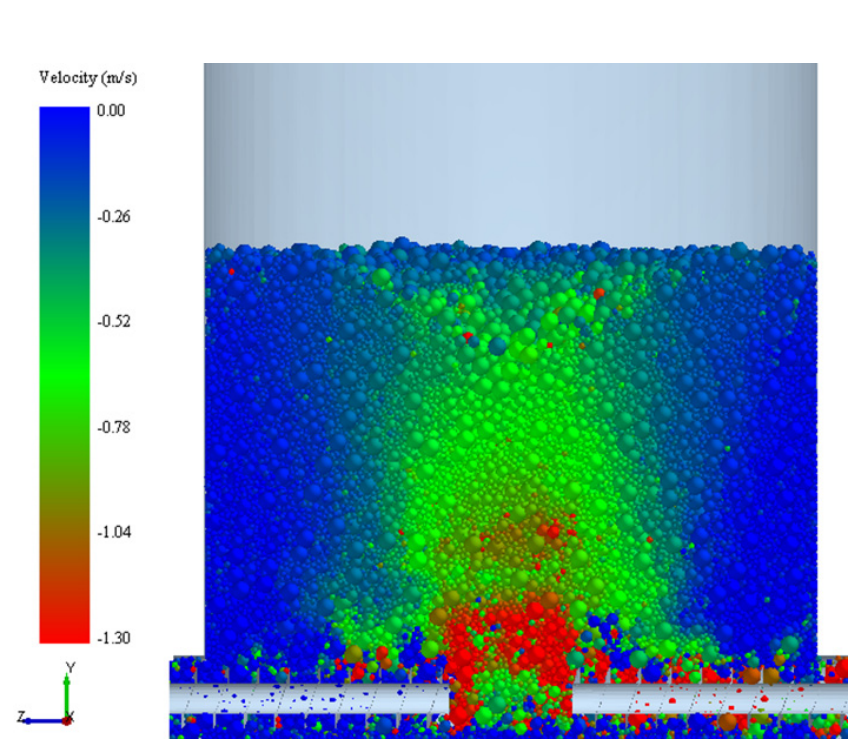

(a)

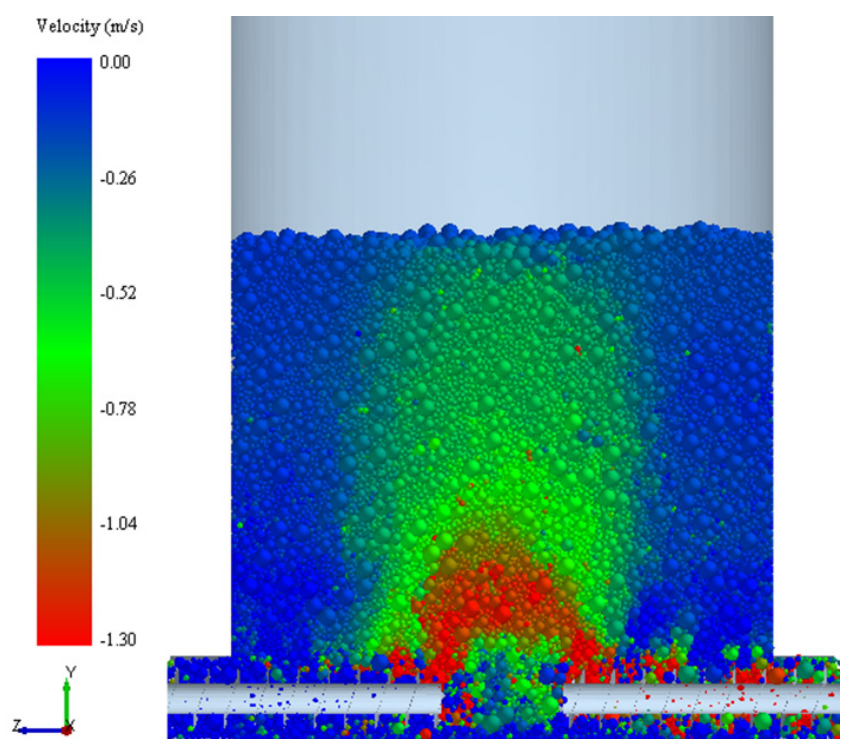

(b)

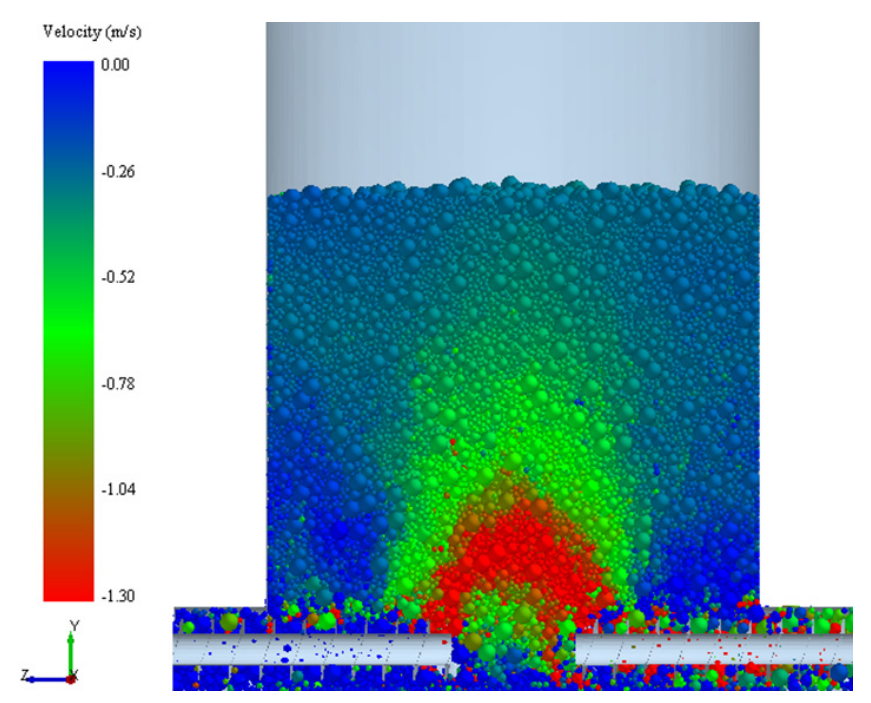

(c)

Fig. 10. Velocity distributions at different diameters of the shaft furnace (a) $10 \mathrm{~m}$ (b) $9 \mathrm{~m}$ (c) $8 \mathrm{~m}$.

order to obtain an evener velocity distribution. Thus, an improved model is established through combining the previous factors. The height of the improved model is $30 \mathrm{~m}$ for the effect of the change of the height on the velocity distribution will be insignificant if the height increases. The diameter of the improved model is $10 \mathrm{~m}$ and the bosh angle is $80^{\circ}$. The cross-section of the velocity distribution in the improved model is illustrated in Figure 15.

It can be seen that the velocity distribution in the improved model is almost uniform. The velocity distributions between the contrast model (the height is $8 \mathrm{~m}$, the diameter is $9 \mathrm{~m}$ and the bosh angle is $90^{\circ}$ ) and the improved model are compared in Figure 16.

The velocity distribution in the improved model seem more uniform than the one in the contrast model. The maximum velocity decreases by $37.6 \%$ and the the minimum velocity increases by $77.4 \%$ compare with that in the contrast model. Specifically, the standard deviation decreases from 0.312 to 0.127 . Therefore, the velocity distribution in the improved model is more reasonable for discharging materials evenly. 


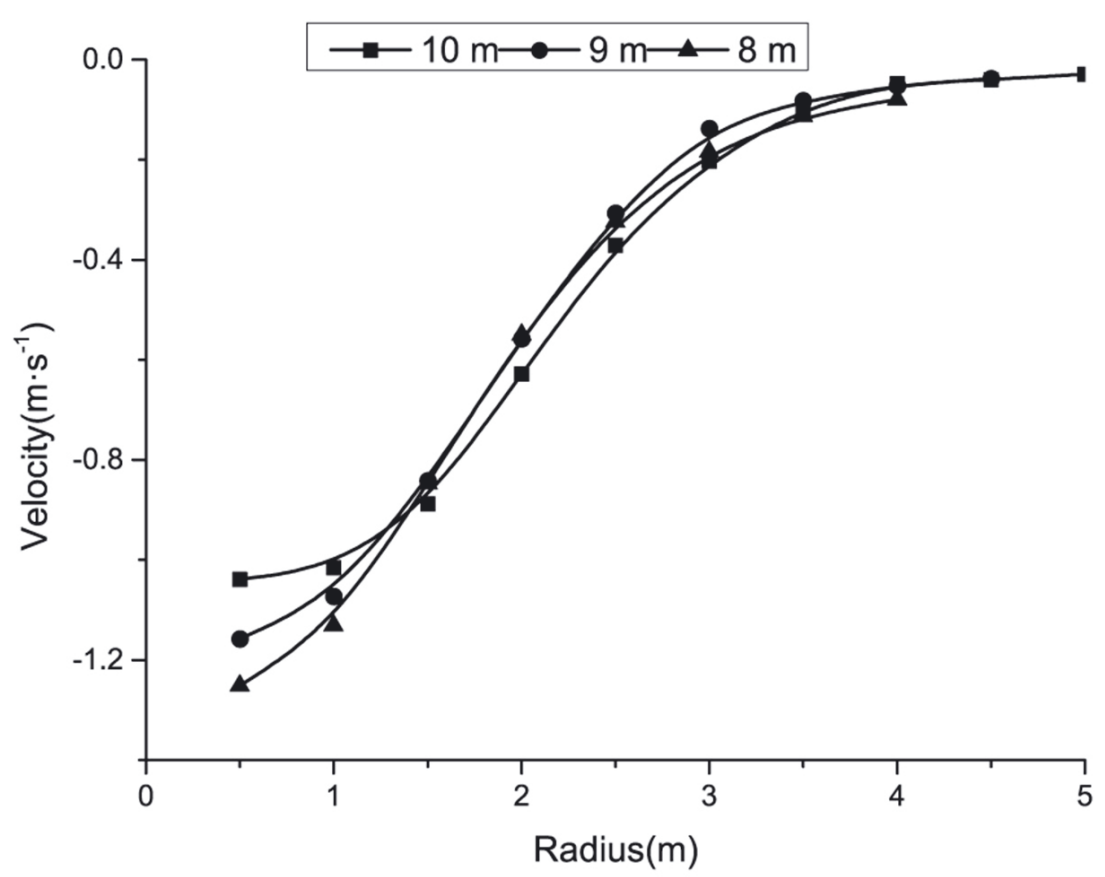

Fig. 11. Velocity along the radius at different diameters of the shaft furnace in level 1.

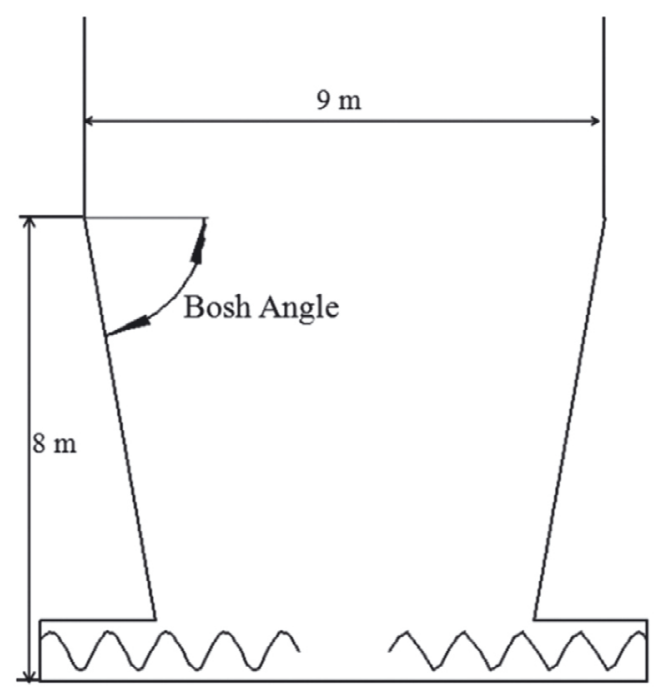

Fig. 12. The schematic diagram of shaft furnace model.

\section{Conclusions}

In order to study the particle descending velocity distribution in the shaft furnace, DEMCFD techniques have been employed and the granular dynamic theory and the Janssen theory have been used to analyze the effect of the factors on the velocity distribution in the present study. The factors simulated in the paper include the gas flow in the shaft furnace, the height, the diameter and the bosh angle of the shaft furnace. Generally, the particle descending velocity reduces from center to wall areas in the shaft furnace.

In terms of the ranges of factors investigated in the paper, the gas flow affects the particle descending velocity most insignificantly under the considered conditions because of the small gas-solid interaction forces. The effect of the shaft furnace height on the velocity distribution is obvious before the height reaches the maximum height, the velocity distribution becomes more uniform with the increase of the height, while the effect of the height on the velocity distribution turns to smaller. Enlarging the shaft furnace diameter restrains the velocities in the center area of the shaft but increases the low velocity area near the wall, while reducing the shaft furnace bosh angle help to narrow the low velocity area beyond $0.4 R$ and decrease the velocities in the others. Therefor, an improved model is established in order to obtain a uniform velocity distribution in the shaft furnace. The improved model has improved the evenness of the velocity distribution obviously, which is provides a numerical basis and technical direction 


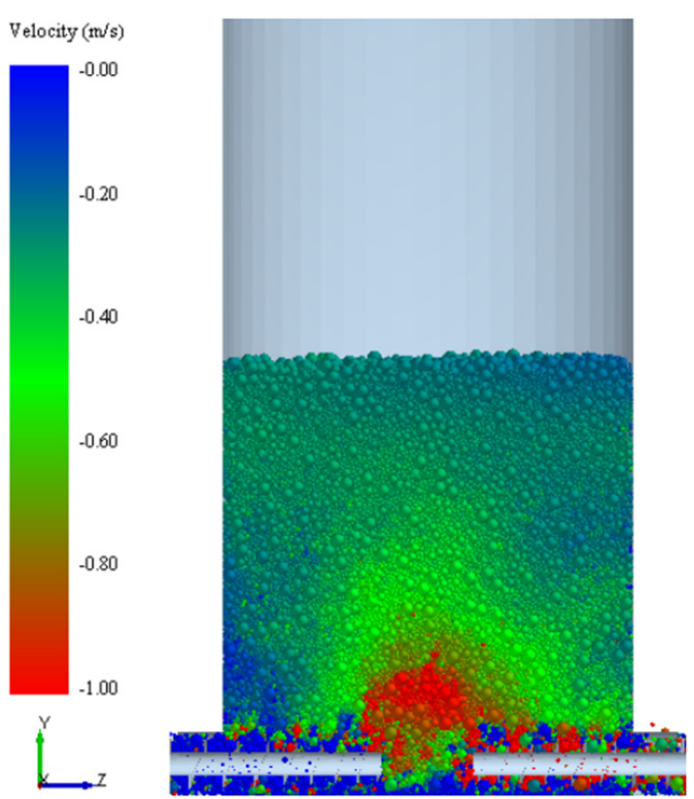

(a)

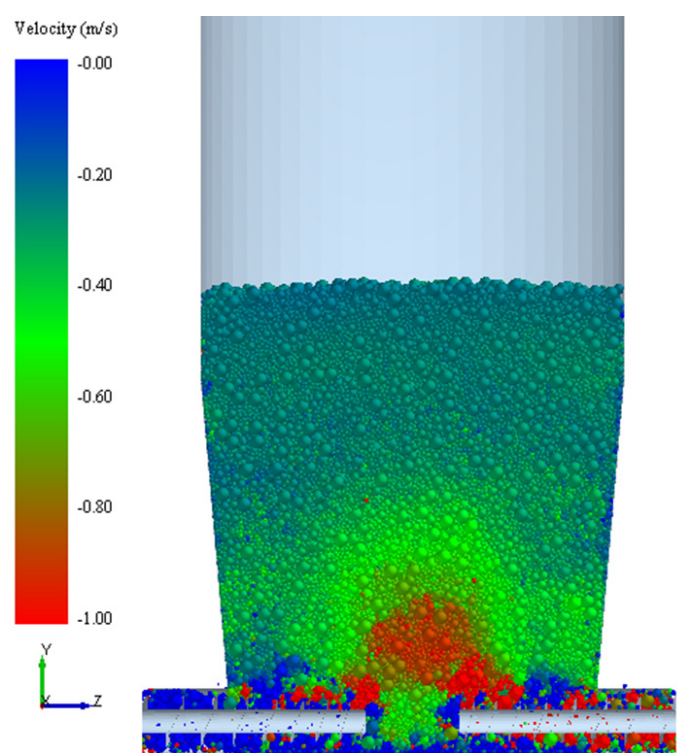

(b)

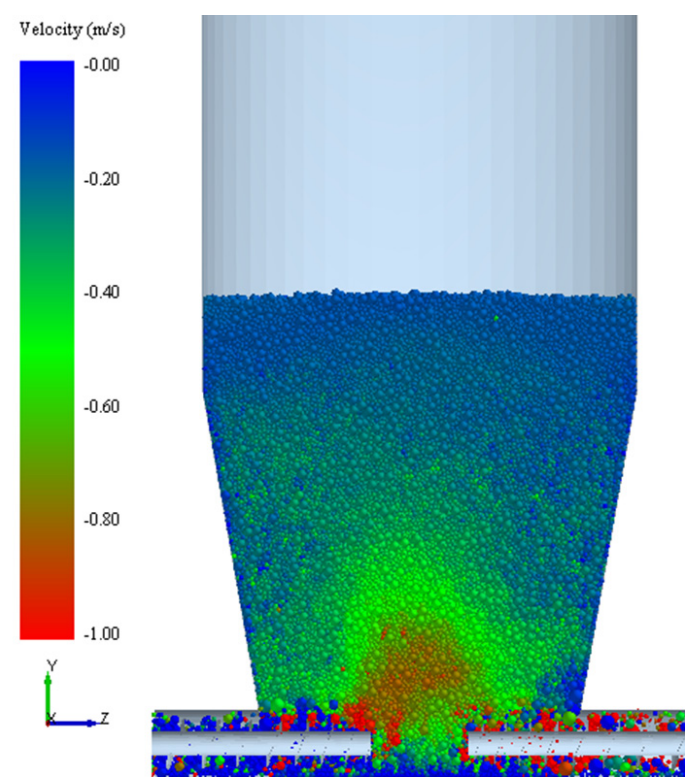

(c)

Fig. 13. Velocity distributions at different bosh angles of the shaft furnace (a) $90^{\circ}$; (b) $85^{\circ}$; (c) $80^{\circ}$.

for the design and improved of the shaft furnace.

This work is an initial explore on the particle descending velocity in the shaft furnace by using DEM-CFD, further simulation will be carry out to investigate the effect of thermo-chemical behavior in the shaft furnace. And the simulation will also take the effect of particle swelling and shrinkage, irregular particle shape, and the sticking force between particles into account inside the entire shaft furnace. Work on these aspects is undertaken and will be reported hopefully in the future.

\section{Acknowledgements}

The author would like to appreciate much for the anonymous reviewers and editors for improvement of this work, and Mr. Guo-ming Xu and Mrs. Lan-xiang Zhang for suggestions on this work. 
K. Xu and M.-H. Bai: Metall. Res. Technol. 113, 603 (2016)

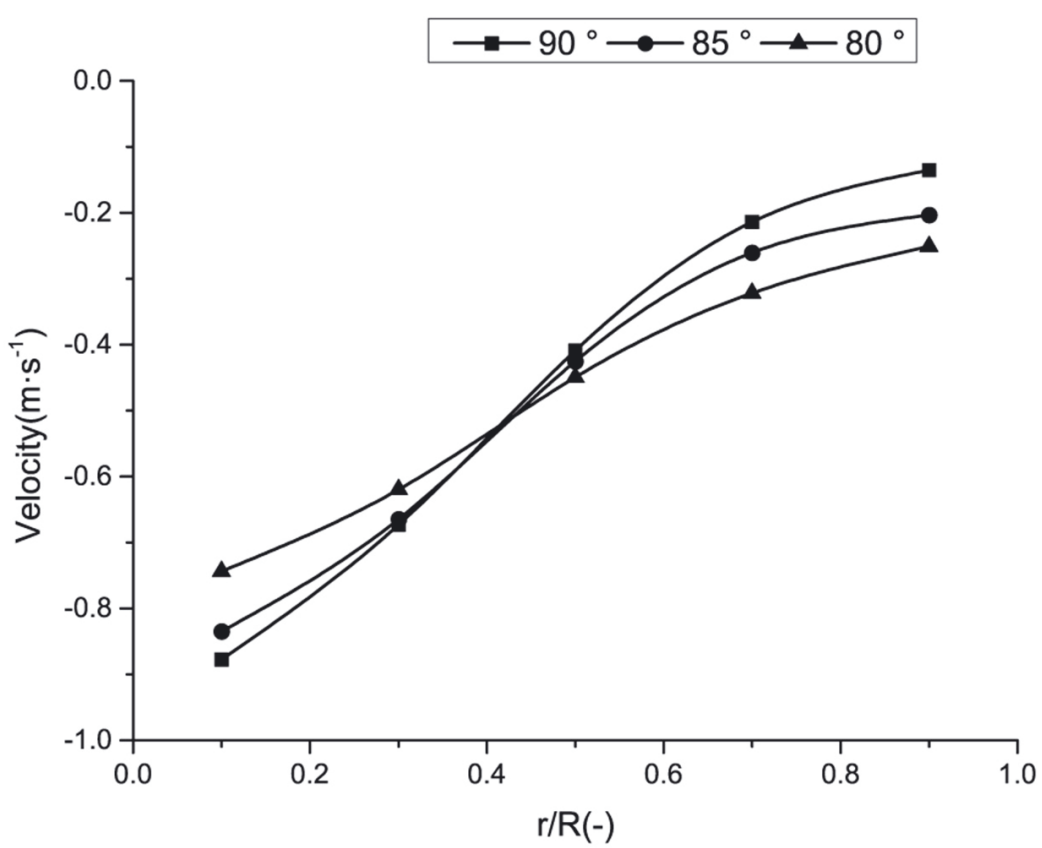

Fig. 14. Velocity along the radius at different bosh angles of the shaft furnace in level 1.

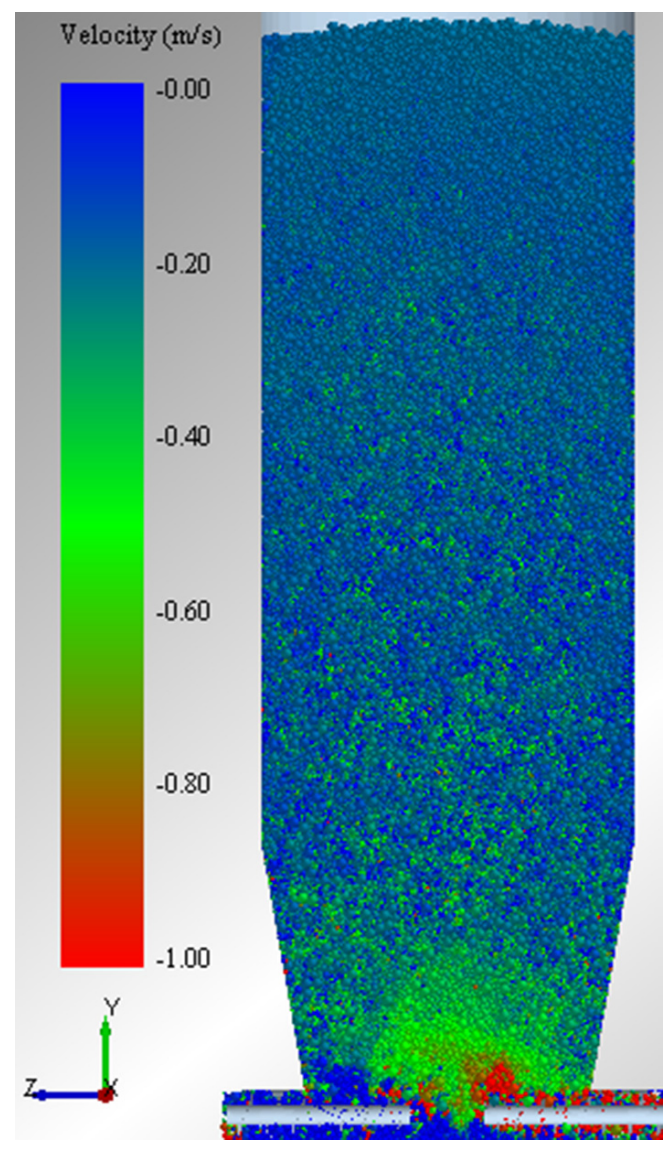

Fig. 15. Velocity distribution in improved model. 


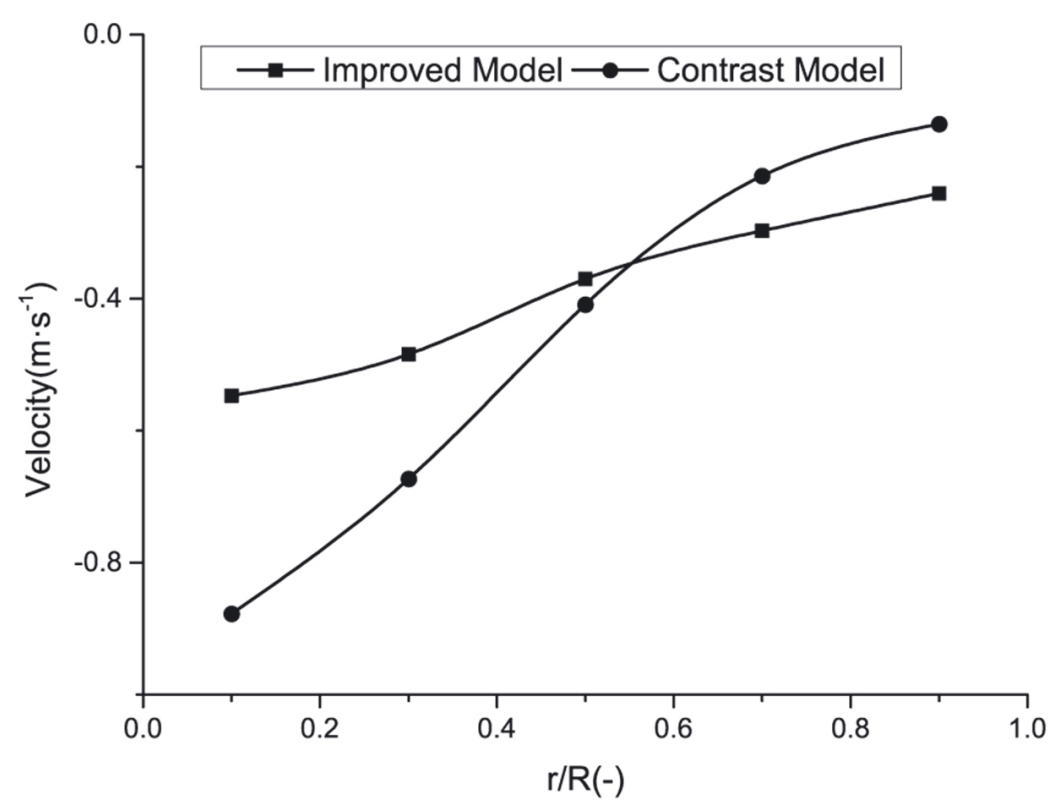

Fig. 16. Velocity along the radius between contrast model and improved model in level 1.

\section{References}

[1] J. Kopfle, R. Hunter, Iron. Steel. 35 (2008) 254259

[2] Y.J. Lee, Powder Technol. 102 (1999) 194-201

[3] H. Zhou, Z.S. Zou, Z.G. Luo, et al., Iron. Steel. 42 (2015) 209-216

[4] H. Zhou, Z. Luo, Z. Zou, et al., Steel Res. Int. 86 (2015) 1073-1081

[5] M. Kou, S. Wu, W. Shen, et al., ISIJ Int. 53 (2013) 2080-2089

[6] H.Zhou, Z.G. Luo, T. Zhang, et al., Iron. Steel. (2015)

[7] M. Kou, S. Wu, K. Du, et al., ISIJ Int. 53 (2013) 1002-1009

[8] H. Mio, S. Komatsuki, M. Akashi, et al., Trans. Iron Steel Instit. Jpn 49 (2009) 479-486

[9] H.A. Janssen, Zeitschr. d. Vereines deutscher Ingenieure 39 (1895) 1045-1049

[10] M. Sperl, Granular Matter 8 (2005) 59-65

[11] R. Balevièius, I. Sielamowicz, Z. Mróz, et al., Powder Technol. 214 (2011) 322-336

[12] P. Xu, X. Duan, G. Qian, et al., Powder Technol. 284 (2015) 326-335

[13] P.A. Cundall, O.D. L.A. Strack, Géotechnique 29 (1979) 47-65

[14] Z.Y. Zhou, H.P. Zhu, B. Wright, et al., Powder Technol. 208 (2011) 72-85

[15] B.H. Xu, A.B. Yu, S.J. Chew, et al., Powder Technol. 109 (2000) 13-26

[16] Z. Zhou, H. Zhu, A. Yu, et al., ISIJ Int. 45 (2005) 1828-1837

[17] Z.Y. Zhou, H.P. Zhu, A.B. Yu, et al., Comput. Chem. Eng. 32 (2008) 1760-1772
[18] Z. Zhou, H. Zhu, A. Yu, et al., Trans. Iron Steel Instit. Jpn 50 (2010) 515-523

[19] Q.F. Hou, Z.Y. Zhou, A.B. Yu, Chem. Eng. Sci. 84 (2012) 449-468

[20] Y.D. Z.iscrete, J. Fluid Mech. 661 (2010) 482510

[21] B.H. Xu, A.B. Yu, Chem. Eng. Sci. 52 (1997) 2785-2809

[22] Y.Q. Feng, B.H. Xu, S.J. Zhang, et al., Aiche J. 50 (2004) 1713-1728

[23] H.P. Zhu, Z.Y. Zhou, R.Y. Yang, et al., Chem. Eng. Sci. 63 (2008) 5728-5770

[24] J.W. Fernandez, P.W. Cleary, W. Mcbrid, Chem. Eng. Sci. 66 (2011) 5585-5601

[25] Y. Yu, H. Saxen, ISIJ Int. 52 (2012) 788-796

[26] H. Guoming, Analysis and simulation of granular system by discrete element method using EDEM, 2010, pp. 7-10

[27] P.J. Owen, P.W. Cleary, Powder Technol. 193 (2009) 274-288

[28] Y. Shimizu, P.A. Cundall, J. Eng. Mech. 127 (2001) 864-872

[29] P.A. Moysey, M.R. Thompson, Polym. Eng. Sci. 44 (2004) 2203-2215

[30] P.A. Moysey, M.R. Thompson, Powder Technol. 153 (2005) 95-107

[31] Y. Yu, P.C. Arnold, Powder Technol. 88 (1996) 81-87

[32] Wu Aixiang, Sun Yezhi and Liu Xiangping, Granular dynamic theory and its application 1st edn, Metallurgical Industry Press of China, Beijing, 2002 